\title{
The Value of Pancasila as Strengthening the Character Building of the Indonesian Nation
}

\section{Teodorikus Hanpalam}

Magister Pendidikan Sejarah Universitas Sebelas Maret teodorikushanpalam@gmail.com

\section{Article History}

accepted 14/03/2021

approved 10/04/2021

published 20/04/2021

\begin{abstract}
This paper aims to: (1). To find out the value of Pancasila as a strengthening of the nation's character building. (2). To instill the value of Pancasila in building national character. (3). As an illustration of the importance of safeguarding the value of Pancasila and strengthening the nation's character in educational institutions. The writing method used in this research is literature study. Benefits of Writing: (1). As a scientific study, this writing can be used as reading material and reference about the value of Pancasila as a reinforcement of the buliding character. (2). For the author to get an overview of how the value of Pancasila is in building the character of the nation. (3). Providing information as an illustration of the value of Pancasila and efforts to build the nation's character.
\end{abstract}

Keywords: Pancasila, character building, educational institutions

\section{Abstrak}

Tulisan ini bertujuan untuk: (1). Untuk mengetahui nilai Pancasila sebagai penguat pembanunan karakter bangsa. (2). Untuk menanamkan nilai Pancasila dalam membangun karakter bangsa. (3). Sebagai gambaran pentingnya penamanan nilai Pancasila dan penguatan karakter bangsa pada isntitusi pendidikan. Metode penulisan yang dilakukan dalam penelitian ini adalah studi literatur. Manfaat Penulisan: (1). Sebagai suatu kajian yang bersifat ilmiah, penulisan ini dapat digunakan sebagai bahan bacaan dan rujukan tentang nilai Pancasila sebagai penguat character buliding. (2). Bagi penulis untuk memperoleh gambaran umum mengenai bagaimana milai Pancasila dalam membangun karakter bangsa. (3). Memberikan informasi sebagai gambaran nilai Pancasila dan upaya pembangunan karakter bangsa.

Kata Kunci: Pancasila, pembangunan karakter, institusi pendidkan

Social, Humanities, and Education Studies (SHEs): Conference Series https://jurnal.uns.ac.id/shes

p-ISSN 2620-9284

e-ISSN 2620-9292 


\section{PENDAHULUAN}

Indonesia merupakan bangsa yang besar dan negara kepulauan yang sangat kaya, memiliki beragam suku, budaya, bahasa dan agama. Realita ini merupakan suatu hal yang patut kita syukuri. Sejak awal berdiri menjadi negara kesatuan, negara Indonesia menganut ideologi dengan nama Pancasila yang yang berarti lima sila sebagai dasar negara dan merupakan hasil kesepakatan para pendiri bangsa. Pancasila juga memiliki peranan penting sebagai titik temu dan penyatu segala perbedaan, karena Pancasila lahir dan terinspirasi dari budaya lokal bangsa Indonesia yang sangat beragam.

Selain itu, Pancasila merupakan jati diri dan ciri khas karakter bangsa Indonesia yang beradab. Bangsa yang beradab artinya bangsa yang memiliki karakter terpuji, apalgi ditengah kemajemukan. Banyak orang yang belum juga menyadari bahwa kemajemukan tersebut juga menyimpan potensi konflik yang dapat mengancam kehidupan berbangsa dan bernegara. Oleh karena itu, kita perlu menyadari dan berupaya untuk penguatan dan karakter kepada pemuda kita sejak dini, terlebih khusus pada institusi pendidikan yang merupakan institusi vital dalam mencetak insan yang bermartabat dan berbudi pekerti luhur sebagaimana diharapkan oleh para pendiri bangsa kita.

Scerenko (1997) mendefenisikan karakter sebagai atribut atau ciri-ciri yang membentuk dan membedakan ciri pribadi, ciri etis, dan kompleksitas mental dari seseorang, suatu kelompok atau bangsa. Sementara itu the free Dictioneri dalam situs onlinenya yang dapat di unduh secara bebas mendifinisikan krakter sebagai suatu kombinasi kualitas atau ciri-ciri yang membedakan seseorang atau kelompok atau suatu benda dangan yang lain. Krakter, juga mendefenisikan sebagai suatu deskripsi dari atribut, ciri-ciri atau kemampuan seseorang.

Pancasila merupakan nilai dasar bangsa yang harus diamalkan oleh setiap warga negara Indonesia. Pancasila yang digali dari dalam diri bangsa Indonesia sendiri harus dipandang sebagai kekuatan batin dalam hidup bermasyarakat, berbangsa, dan bernegara.

Pembangunan Karakter juga menjadi modal utama untuk mencapai tujuan bersama dan keyakianan akan nilai-nilai luhur kebangsaan. Nilai luhur yang dimaksud adalah semangat persatuan dan kesatuan, cinta tanah air, dan mengutamakan kepentingan bersama, kewaspadaan terhadap ancaman disintegrasi, bangga sebagai anak bangsa, serta sikap rela berkorban dan toleransi terhadap sesama.

Pemahaman nilai-nilai Pancasila pada anak bangsa akan menjadi fundasi yang kuat untuk diterapkan di dalam kehidupan sekolah maupun dalam masyarakat. Melalui nilai-nilai yang terkandung di dalamnya, diharapkan dapat membangkitkan semangat persudaraan dan tenggang rasa, gotong royong dan toleransi yang mengikat perbedaan. Hal inilah yang diharapkan memberikan motivasi anak bangsa dalam rangka pembentukan karakter yang tangguh, tekun, ulet, rajin, rela berkorban, saling menghargai, kreatif dan inovatif.

Apabila Pancasila menyatu dalam karakter siswa, maka anak bangsa akan lebih menghargai sesama, punya semangat juang, serta rasa toleransi yang tinggi terhadap kebhinekaan.

Bangsa yang besar adalah bangsa yang punya cita-cita besar dan selalu mengedepankan nilai-nilai adiluhung masyarakaatnya. Itu syarat mutlak yang telah diuji sejarah di setiap masa. Kalau kita tidak menghargai warisan itu dan mengabaikannya kita hanya akan menjadi bangsa yang halusinasinya besar. 


\section{METODE}

Metode penelitian yang dipakai dalam penelitian ini adalah metode kualitatif dengan strategi penelitian studi literatur. Sumber dan metode pengumpulan data dengan mengambil dari data di pustaka, internet berupa artikel ilmiah, buku, jurnal dan dokumen serta refrensi lain yang terkait dengan tema penelitian kemudian membaca, mencatat dan mengolahnya menjadi sebuah karya ilmiah.

\section{HASIL DAN PEMBAHASAN}

Sejak disahkan secara konstitusional pada 18 Agutustus 1945, Pancasila dapat dikatakan sebagai dasar negara, pandangan hidup, ideologi negara dan ligatur (pemersatu) dalam perikehidupan kebangsaan dan kenegaraan IndonesiaSebagai falsafah negara, Pancasila merupakan hasil dari gagasan original dan pergulatan tokoh bangsa yang multi etnis. Sejarah panjang sebelum disepakatinya Pancasila sebagai dasar negara menjadi acuan bahwa Pancasila tidak semata mata berdiri sendiri atau tiba-tiba muncul sebagai fundasi untuk menyatukan seluruh rakyat Indonesia. Ada proses sejarah diakronis yang menggugah semangat persatuan atas dasar kesamaan nasib dalam menghadapi musuh bersama (common enemy). Selain itu, Pancasila bukan hanya sebagai dasar maupun pedoman dalam bernegara namun merupakan cita-cita dan tujuan negara. Pancasila juga memiliki fungsi dan keududukan yang mengandung nilai penguatan karakter bangsa.

Fungsi dan tujuan Pancasila sudah sangat jelas dan termaktub dalam poin-poin yang terkandung serta segenap perangkat turunannya yang lain. Nilai yang mengacu pada pembangunan karakter tertera pada sila kedua telah mengisi rumusan-rumusan yang telah ditetapkan dan sudah sangat terang benderang bahwa Pancasila memiliki tujuan besar untuk membangun karakter bangsa Indonesia.

Bangsa Indonesia diharapkan dan diarahkan untuk bersikap terbuka namun tetap berpegang teguh pada prinsip-prinsip dasar. Sebagai identitas dan jati diri suatu bangsa, karakter merupakan nilai dasar atau prilaku yang menjadi acuan tata nilai interaksi antara manusia.

Karakter seseorang akan terbentuk tergantung dari lingkungan kehidupan yang dijalaninya. Dengan bantuan pendidikan formal seperti sekolah, maka akan membantu dalam pembentukan karakter melalui penerapan pendidikan karakter di sekolah yang diintegrasikan dengan mata pelajaran.

Secara universal sebagai karakter dirumuskan sebagai niali hidup bersama berdasarkan atas pilar: kedamain (peace), menghargai (respect), kerja sama (coorperation), kebebasan (freedoom), kebahagiaan (happiness), kejujuran (honesty), kerendahan hati (humility), kasih sayang (love), tanggung jawab ( responbility), kesederthanaan (simpalicity), toleransi (tolerance), dan persatuan (unity). Dalam sila kedua yang berbunyi , Kemanusiaan yang adil dan beradab adalah kemanusiaan yang memiliki karakter yang adil dan beradab, yang bisa menghargai sesamanya, mencintai keberagaman dan berbudi luhur.

Sila kedua juga menuntut kewajiban moral terhadap diri sendiri, pengakuan dan penghormatan terhadap harkat dan martabat manusia (dignity of man), nilai-nilai kemanusiaan (human value), hak asasi manusia (human right), dan kebebasan manusia (human freedom). (Materi Sosialisasi Empat Pilar). Artinya kita sebagai bangsa Indonesia diarahkan untuk memiliki karakter terpuji dengan mengakui perbedaan, menghormati harkat dan martabat orang lain, memiliki nilai-nilai kemanusiaan dan menghargai kebebasan manusia yang melekat pada diri dan identitasnya.

Menurut Yudi Latif (2011) dalam silah kedua alam pemikiran Pancasila yaitu, nilai-nilai kemanusiaan universal yang bersumber dari hukum Tuhan, hukum alam, dan sifat-sifat sosial manusia (yang bersifat horizontal) dianggap penting sebagai fundamen etika-politik kehidupan bernegara dalam pergaulan dunia. Prinsip kebangsaan yang 
luas yang mengarah pada persaudaraan dunia itu dikembangkan melalui jalan eksternalisasi dan internalisasi. Secara eksternalisasi bangsa Indonesiamenggunakan segenap daya dan khazanah yang dimilikinya untuk secara bebas -aktif 'ikut melaksanakan ketertiban dunia yang berdasarkan kemerdekaan, perdamaian abadi dan keadilan sosial', dan secara internalisasi bangsa Indonesia mengakui dan memuliakan hak-hak dasar warga dan penduduk negeri. Landasan etik sebagai prasyarat persaudaraan universal ini "adil" dan "beradab".

Komitmen bangsa Indonesia dalam memuliakan nilai-nilai kemanusiaan itu sangat visioner, mendahului "Universal Declaration of Human Rights" yang baru dideklarasikan pada tahun 1948. Artinya nilai-nilai kemanusiaan yang adil dan beradab merupakan nilai yang digali dari budaya adiluhung bangsa Indonesia dan merupakan jati diri yang bisa menjadi acuan kita pada masa kini dalam membangun peradaban dan karakter unggul anak bangsa agar bisa bersaing dengan bangsa lain di dunia.

Bangsa yang besar adalah bangsa yang punya cita-cita besar dan selalu mengedepankan nilai-nilai adiluhung masyarakaatnya. Itu syarat mutlak yang telaah diuji sejarah di setiap masa. Kalau kita tidak menghargai warisan itu dan mengabaikannya kita hanya akan menjadi bangsa yang halusinasinya besar.

Warsono dkk. (2010) mengutip Jack Corley dan Thomas Philip (2000) menyatakan: "Karakter merupakan sikap dan kebiasaan seseorang yang memungkinkan dan dan mempermudah tindakan moral."

Muchlas Samani, Hariyanto M.S. (2012, 41-46) Akar dari semua tindakan yang jahat dan buruk ,tindakan kejahatan terletak pada hilangnya karakter. Karakter yang kuat adalah sandangan fundamental yang memberikan kemampuan kepada populasi manusia untuk hidup bersama dalam kedamaian serta membentuk dunia yang di penuhi dengan kebaikan dan kebajikan, yang bebas dari kekerasan dan tindakan tindakan tidak bermoral. Institusi pendidikan memiliki tanggungjawab moral agar generasi muda Indonesia sejak dini bisa mengamalkan nilai-nilai Pancasila dan memiliki karakter unggul.

Membangun budaya berperilaku di sekolah dituangkan dalam tata tertib sekolah, peraturan di sekolah, seperti cara berpakaian yang sopan, dilarang merokok, tidak berkata kasar dan kotor, disiplin waktu, menjaga ketertiban dan kebersihan, keindahan dan keamanan sekolah.

Menurut Retno Listyarti $(2012 ; 10)$ alasan sekolah wajib melakukan pendidikan karakter sebagai berikut:

a. Karena karakter bangsa Indonesia masih lemah

b. Sejalan dengan Renstra Kemendiknas 2010-2014 yang mencanangkan penerapan karakter, maka diperlukan kerja keras semua pihak terutama terhadap programprogram yang memiliki kontribusi besar terhadap peradaban bangsa

c. Penerapan pendidikan karakter di sekolah memerlukan pemahaman konsep, teori metodologi, dan aplikasi yang relevan dengan pembentukan karakter (character building) dan pendidikan karakter (character education).

Jadi, pendidikan karakter adalah proses pemberian tuntunan kepada peserta didik untuk menjadi manusia seutuhnya yang berkarakter dalam dimensi hati, pikir, raga, serta rasa dan karsa. Pendidikan karakter dapat dimaknai sebagai pendidikan nilai, pendidikan budi pekerti, pendidikan moral, pendidikan watak, yang bertujuan mengembangkan kemampuan peserta didik untuk memberikan keputusan baik-buruk, memelihara apa yang baik, dan mewujudkan kebaikan itu dalam kehidupan sehari-hari dengan sepenuh hati.

Narwanti (2011:16) Pendidikan karakter pada intinya bertujuan membentuk bangsa yang tangguh, kompetitif, berakhlak mulia, bermoral, bertoleran, bergotong royong, berjiwa patriotik, berkembang dinamis, berorientasi ilmu pengetahuan dan teknologi yang semuanya dijiwai oleh iman dan takwa kepada Tuhan Yang Maha Esa berdasarkan Pancasila. 
Tujuan pendidikan karakter dapat disimpulkan oleh peneliti bahwa, dengan pendidikan karakter diharapkan dapat mewujudkan peserta didik yang memiliki akhlak mulia, dapat mematuhi aturan yang ada, bersikap selalu berpegang teguh pada aturan dan tidak menyimpang.Peserta didik sebagai generasi penerus harus mampu membawa bangsa dan negaranya menuju ke arah yang lebih baik.Selain itu, dengan pendidikan karakter maka dapat mewujudkan manusia yang bermoral, berbudi pekerti dan berjiwa kreatif.

Dalam Undang-Undang Nomor 20 Tahun 2003 tentang Sistem Pendidkan Nasional dirumuskan dalam pasal 3: 'Pendidikan Nasional bertujuan untuk berkembangnya potensi peserta didik agar menjadi manusia beriman dan bertaqwa kepada Tuhan Yang Maha Esa, berakhlak mulia, sehat, berilmu, cakap, kreatif, mandiri, dan menjadi warga negara yang demokratis serta bertanggung jawab.".

Sedangkan fungsi pendidikan nasional dirumuskan : " mengembangkan kemampuan dan membentuk watak serta peradaban bangsa yang bermartabat dalam rangka mencerdaskan kehidupan bangsa.

Sri Judiani (2010:282) membagikannya dalam tiga fungsi sebagai berikut:

1. Fungsi pengembangan

Pengembangan potensi peserta didik untuk menjadi pribadi berprilaku baik, terutama bagi peserta didik yang telah memiliki sikap dan prilaku yang mencerminkan karakter bangsa.

2. Fungsi perbaikan

Memperkuat kiprah pendidikan nasional untuk bertanggung jawab dalam pengembangan potensi peserta didik yang bermartabat.

3. Fungsi penyaring

Pendidikan karakter berfungsi untuk menyelekdi budaya bangsa sendiri dan budaya lain yang tidak sesuai dengan nilai karakter yang bermartabat.

Adapun acuan pendidikan karakter diantaranya:

Pertama, UU nomor 20 tahun 2003 tentang sistem pendidikan. Pasal 2 menjelaskan bahwa "Pendidikan Nasional berdasarkan Pancasila dan Undang-Undang Dasar Republik Indonesia Tahun 1945".

Dengan dicantumkannya Pendidikan Dasar Pancasila mengandung arti bahwa untuk mencerdaskan kehidupan bangsa atau membangun karakter/budi pekerti adalah berdasarkan nilai-nilai luhur Pancasila yang dirumuskan dalam Undang-Undang Dasar 1945. Pasal 3 merumuskan dengan tegas bahwa "Pendidikan nasional berfungsi meengembangkan kemampuan dan membentuk watak serta peradaban bangsa yang bermartabat dalam rangka mencerdaskan kehidupan bangsa, bertujuan untuk berkembangnya potensi peserta didik agar menjadi manusia yang beriman dan bertaqwa kepada Tuhan Yang Maha Esa, berakhlak mulia, sehat, berilmu, cakap, kreatif, mandiri, dan menjadi warga negara yang demokratis serta bertanggung jawab. Pasal 36 (3) Undang-Undang Sistem Pendidikan Nasional: Kurikulum disusun sesuai dengan jenjang pendidikan dalam rangka NKRI dengan memperhatikan:

a) Peningkatan iman dan taqwa

b) Peningkatan akhlak mulia

c) Peningkatan potensi, kecerdasan dan minat peserta didik

d) Keragaman potensi dan lingkungan

e) Tuntutan pembangunan daerah dan nasional

f) Tuntutan dunia kerja

g) Perkembangan ilmu pengetahuan, teknologi, dan seni

h) Agama

i) Dinamika perkembangan global

j) Persatuan nasional dan nilai-nilai kebangsaan".

Kedua, Undang-Undang Republik Indonesia Nomor 17 Tahun 2007 tentang RPJPN 2005-2025: "bahwa pembangunan bangsa yang berkarakter bercirikan bangsa yang 
tangguh, kompetitif, berakhlak mulia, bermoral, bertoleran, bergotong royong, patriotik, dinamis, berbudaya, dan berorientasi ipteks berdasarkan Pancasila dijiwai oleh iman dan taqwa kepada Tuhan Yang Maha Esa."

Dalam Undang-Undang Nomor 17 Tahun 2007 tersebut dijelaskan pula tahap-tahap pembangunan nasional:

Tahap I: 2010-2014

a) Reorientasi dan penyadaran akan pentingnya pembangunan karakter bangsa

b) Penyusunan perangkat kebijakan terpadu dan pemberdayaan pemangku kepentingan agar dapat melaksanakan pembangunan karakter bangsa secara efektif.

Tahap II: 2014-2020:

a) Pengukuhan nilai-nilai dalam karakter bangsa dan pemantapan pelaksanaan pembangunan karakter bangsa serta evaluasi pelaksanaannya.

b) Pelaksanaan pemantapan dan evaluasi pembangunan karakter bangsa.

Tahap III: 2020-2025:

Pengembangan berkelanjutan

\section{SIMPULAN}

urain diatas dapat ditarik kesimpulan bahwa Pancasila sangat erat kaitannya dengan penguatan karakter bangsa terutama dalam institusi pendidikan yang memiliki pengaruh terhadap karakter siswa, sehingga diharapkan siswa bisa saling menghargai, tumbuh rasa tenggang rasa, persaudaraan, gotong royong, dan rela berkorban serta lebih mencintai negara dalam bingkai persatuan dan kesatuan sebagai anak bangsa. Melalui pembelajaran sejarah diharapkan dapat membentuk pribadipribadi yang memiliki karakter yang kuat, menghargai keanekaragaman masyarakat yang multikultural serta memiliki rasa tanggung jawab terhadap masa depan bangsa, persatuan dan kesatuan, serta keutuhan Negara Kesatuan Republik Indonesia

Pendapat tersebut diatas menjadi penegasan bahwa bangsa yang beradab memiliki suatu struktur dan sistem yang mempunyai dasar yang jelas sebagai sebuah falsafah sekaligus cita-cita dalam rangka memelihara harkat dan martabat manusia serta mengatur seluruh hajat hidup serta menjamin terpeliharannya norma-norma yang berlaku dalam kehidupan masyarakat yang multikultural secara egaliter.

\section{DAFTAR PUSTAKA}

Amin, Maswardi M. (2015). Pendidikan Karakter Anak Bangsa. Yogyakarta. Calpulis Judiani, Sri, 2010. Implementasi Pendidikan Karakter di Sekolah Dasar Melalui Penguatan Pelaksanaan Kurikulum. Jakarta: Jurnal Pendidikan \& Kebudayaan Vol. 16, Edisi Khusus III, Oktober 2010.

Kementerian Pendidikan Naional. (2010). Peengembangan Pendidikan Budaya dan Karakter Bangsa. Bahan Pelatihan Penguatan Metodologi Pembelajaran Berdasarkan Nilai-nilai Budaya Untuk Membentuk Daya Saing dan Karakter Bangsa. Jakarta, Kementerian Pendidikan Nasional.

Latif, Yudi, Pancasila Dasar Dan Haluan Negara, Makalah Dalam Lokakarya Empat Pilar Kehidupan Berbangsa Dan Bernegara, (Jakarta: MPR RI, 17-19 Juni 2011)

Listiyarti, Retno. (2012). Pendidikan Karakter dalam Metode Aktif, Inovatif \& Kreatif. Jakarta:

MATERI SOSIALISASI EMPAT PILAR MPR RI, 2016. Cetakan Keenam. Jakarta: Sekertariat Jendral MPR RI.

Muchlas Samani dan Hariyanto. (2011). Konsep dan Model Pendidikan Karakter. Bandung: PT Remaja Rosdakarya.

Mu'in Fatchul. (2011). Pendidikan Karakter, Konstruksi Teoretik \& Praktik. Jogjakarta, Ar-Ruzz Media. 
Muslich, Masnur. (2011). Pendidikan Karakter, Menjawab Tantangan Krisis Multidimensional. Jakarta, Bumi Aksara Scerenko, Linda C. 1997. Values and Character Education Implementation Guide, Georgia Department of Education.

Narwanti, Sri. (2011). Pendidikan Karakter. Yogyakarta: Familia.

Undang-Undang Nomor 20 Tahun 2003 tentang Sistem Pendidikan Nasional 